\title{
Educational research, culturally distinctive epistemologies and the decline of truth
}

European Educational Research Journal 2019, Vol. 18(5) 513-526

(C) The Author(s) 2019

Article reuse guidelines: sagepub.com/journals-permissions DOI: 10.1 I77/|474904| I 9840 I74 journals.sagepub.com/home/eer

(S)AGE

\section{Kai Horsthemke}

KU Eichstätt-Ingolstadt, Germany

\begin{abstract}
The assumptions underlying this contribution are, first, that educational research, like research in other fields, is expected to yield knowledge. This is rather uncontroversial. It is only when it comes to the definition of knowledge, the kinds of knowledge sought and to questions as to whose knowledge counts, that the debate characteristically becomes more heated. Second, and perhaps more controversially, a discussion of the nature and purposes of educational research will, at some stage, have to engage with the notion of truth. Despite having traditionally been a serious philosophical subject, the idea of truth has in recent times become rather unpopular, an idea non grata. The reconceptualisation of knowledge and the decline of truth are due in no small part to the increased popularity of certain kinds of postcolonial theory, postmodernism, constructivism and feminist thought, the rise of subaltern science and alternative epistemologies in academia. This article critically examines current trends in the theory of educational research: the case against 'crypto-positivism' and 'hyperrationality', and the trend in favour of 'epistemological diversity' and 'critical constructivist epistemology', especially against the backdrop of the decline of truth as a significant subject and yardstick that is currently exercising and restraining us, as educational researchers, philosophers and as persons.
\end{abstract}

\section{Keywords}

Epistemology, diversity, knowledge, truth, educational research

\section{Introduction}

The assumptions underlying this contribution are, first, that educational research, like research in other fields, is expected to yield knowledge. This appears to be rather uncontroversial. It is only when it comes to the definition of knowledge, the kinds of knowledge sought and to questions as to whose knowledge counts, that the debate characteristically becomes more heated. Second, and perhaps more controversially, a discussion of the nature and purposes of educational research must, at some stage, engage with the notion of truth. Indeed, as Richard Pring (2000: 146) has pointed 
out, "The overriding principle which informs research would seem to be that of "finding the truth". Despite having traditionally been a serious philosophical subject, the idea of truth has in recent times become rather unpopular, an idea non grata. The reconceptualisation of knowledge and the decline of truth as a central preoccupation of philosophy in its various forms and traditions are due in no small part to the rise of certain kinds of postcolonial theory, postmodernism, constructivism and feminist thought, not to mention the increased popularity of subaltern science and alternative epistemologies in academia. In this regard, this article focuses on current trends in the theory of educational research:

- the case against scientism, 'crypto-positivism' and 'hyperrationality' (Kincheloe, 2015a; Kincheloe and Tobin, 2015a, 2015b);

- the trend in favour of culturally distinctive epistemologies and 'critical constructivist epistemology' (Kincheloe, 2015a, 2015b; Kincheloe and Tobin, 2015a, 2015b; Pallas, 2001), 'bricolage' and the 'spirit of multilogicality' (Berry, 2015; Kincheloe, 2015a, 2015b; Kincheloe and Tobin, 2015a, 2015b; Steinberg, 2015; Tobin and Steinberg, 2015a).

My aim is to point out some misconceptions at work in these writings. I critically examine the arguments against some of the pet targets of what Paul Gross and Norman Levitt (1998) have disparagingly and tendentiously referred to as 'the academic left', a diverse group that includes various kinds of postmodernists and constructivists, ethnoepistemologists, bricoleurs and culturalists. I then interrogate the notions of epistemological diversity, research as bricolage and the idea of multiple truths, especially against the backdrop of the decline of truth as a significant subject and yardstick that is currently exercising and indeed restraining us, as educational researchers, philosophers and as persons.

My argument is that truth matters, in the so-called 'foundation disciplines' of educational research as elsewhere, and that there is ultimately no consistent and coherent substitute for scholarly care, thoroughness and rigour in argumentation and disputation.

\section{The case against 'scientism', 'crypto-positivism' and 'hyperrationality'}

The authors in the second edition of Doing Educational Research target 'a pervasive scientism that embraces tenets of crypto-positivism' and address 'logics of inquiry, underpinning cutting-edge approaches to educational research that extend far beyond limited visions that are presented through the lenses of positivism' (Tobin and Steinberg, 2015b: back cover blurb). They distinguish between 'epistemological projects that embody narrow, particular, positivist approaches to "scientific" and "evidence-based" research' and 'other kinds of evidence and knowledge', such as 'qualitative, interpretive and community-based participatory research, as well as different kinds of local knowledge', all of which have been marginalised or excluded by the former approaches (Holzmeyer and Willinsky, 2015: 455; Tobin and Steinberg, 2015a: xliii).

Before I address the objections in greater detail, it might be worthwhile to examine the respective understandings of the concepts in questions. 'Scientism' refers to the belief that for something to qualify as knowledge it must have the form it has in the physical sciences. Positivism is defined as 'an epistemological position that values objective, scientific knowledge produced in rigorous adherence to the scientific method'; it sees knowledge as 'worthwhile to the extent that it describes objective data that reflect the world' (Kincheloe, 2015b: 291). 'Crypto-positivism', or 'neo-positivism', refers to the 'covert operatives' of positivism 'in the contemporary world' (Kincheloe, 
2015a: xxxviii) and might also be characterised as 'hidden positivism' (Kincheloe and Tobin, 2015b: 22). This 'neo-positivist educational research continues the objectivist tradition of viewing everything from a transcultural, transhistorical nowhere' (Kincheloe and Tobin, 2015b: 27). This is contrasted with 'culturalism':

[t]he ideology of a politicised category of people classified according to a shared history and 'race'. The emphasis is on the group's 'culture' as a political as well as a social category. A person's experience as a member of that culture is regarded as the basis of knowledge [and of all educational research]. Both constructivism and culturalism reject the main idea of modernity - the universal reasoning subject. (Rata, 2012: 2)

Finally, hyperrationality (or hyperrationalism) involves an 'instrumental rationality', 'an obsession with means rather than ends, methods, procedure, and efficiency rather than an effort to understand the world so we can better serve the needs of human beings', and that "limits questions to "how to" rather than "why should"" (Kincheloe and Tobin, 2015a: 5). Although Kincheloe and Tobin claim that 'resistance to such hyperrationalism does not necessitate the embrace of an irrationality characterised by a nihilism and relativism that offer no hope for scholarly growth or ethical action', it is difficult to see how their position is able to avoid this charge, as I will show below.

In Joe Kincheloe's (2015a: $\mathrm{x}$ ) analysis, and in agreement with Kenneth Tobin, 'positivist approaches to knowledge production' with their emphasis on objectivity and neutrality are reductionist, 'profoundly limited and account for very narrow dimensions of human experience'. In contrast, 'social theoretical insight' establishes the essential 'subjectivity and context-dependency of knowledge production' (Kincheloe and Tobin, 2015a: 7). The positivist conception of 'rigorous thinking' refers to 'a mode of cognition based on an unproblematised use of reason' (Kincheloe, 2015a: xi). This orientation ignores 'the complex contextual, process-oriented, and ideological factors at work in any analysis and research process', like 'autobiographical insights and examples of what the researcher was thinking as he or she was designing and conducting research' (Kincheloe, 2015a: xi). The latter research processes lead 'into a new epistemological, ontological and ideological territory - a terrain where objects in the mimetic researcher's rearview mirror may be more complex than we ever imagined' (Kincheloe, 2015a: xii). Instead of contradictions and incongruencies being treated as errors, to be erased 'in the quest for final truth', they ought to be viewed 'as propitious moments where deeper insight into the data can be gained into the domain under study' (Kincheloe, 2015a: xiii). By bringing 'together patterns of coherence with these conflicts', the mindful researcher 'gains a more textured view of the phenomenon under study' (Kincheloe, 2015a: xiii).

'An unproblematised use of reason' is presumably involved in the conception of research as a 'cold, rational process' (Steinberg, 2015: 121), as necessarily completely devoid of passion, emotion and empathy, all of which are designated inferior forms of consciousness. 'Feminist research', by contrast, inserts 'feeling, empathy, and the body into the act of inquiry, blurring the distinction between knower and known, viewer and viewed - looking at truth as a process of construction in which knowers and viewers play an active role' (Steinberg, 2015: 121), and injecting passion into the research. Feminist researchers reject 'the authority of the certainty of science' and consider the purported objectivity of modernist science to be tantamount to an abdication of 'social and ethical responsibility, ideological passivity, and the acceptance of privileged socio-political position of the researcher' (Steinberg, 2015: 121). They argue that 'modernist pseudo-objectivity demands the separation of thought and feeling, the devaluation of any perspective maintained with emotional conviction', and that 'those who rely on thought or logic operating within this framework can justify their repression of those associated with emotion or feeling' (Steinberg, 2015: 121; emphasis added). 
Shirley Steinberg and feminist theorists are surely right in pointing out that the human perspective is both inescapable and indeed an asset in educational research, as elsewhere, and in contesting the separation of reason and emotion, of thought and feeling. As Julian Barnes (1997: 127) has put it so trenchantly, one can be 'sentimental about clarity of thought, emotional about rationality'. However, mere emotional conviction will hardly make a perspective compelling. To maintain, as Kincheloe does (2015a: xxxiii), that the 'concept of rationality is used to cover up what we don't know about the world, about the moment in which we are living', is to demonise rationality and 'Western reason' (Kincheloe and Tobin, 2015b: 15) by way of bald assertion and in a manner that is plainly inconsistent. If 'educational reforms based on decontextualised, rationalistic research remove teachers and students from an understanding of the compelling intellectual and political issues of the day' (Kincheloe and Tobin, 2015a: 11), then what sense can one possibly make of such an understanding in the absence of reason and rationality? ${ }^{1}$

I cannot help but think that this attack on reason and science, in the form of 'scientism' and 'crypto-positivism', amounts to much ado about surprisingly little. Even if some forms of these reviled orientations have survived into the 21 st century, their influence and impact on educational research have waned considerably, all things considered. Furthermore, not only does this vociferous 'exposure' fail to acknowledge the important role that reason continues to play in research (and that it is often perfectly compatible with feeling and empathy, especially epistemic empathy), but it also fails to spell out what educational research would look like and what it could achieve in the absence of evidence, rational inquiry and a quest for objectivity. Evidence-based research may not be very helpful in some regards, like helping us to 'answer questions about the purpose of schools' or 'about strategies for reform', or normative 'questions about the control of knowledge' (Kincheloe and Tobin, 2015a: 7), but rational, philosophical argumentation certainly is. On the other hand, evidence-based research may well help us to understand other phenomena listed by Kincheloe and Tobin, namely how 'the existence of socio-economic inequality along the axes of race, class, gender, sexuality, physical ability, religion and language influence the way we approach research', or to discover 'covert political agendas that motivate the research and research policies of particular political and educational leaders' (Kincheloe and Tobin, 2015a: 7). To give a further example, a considerable body of research shows that there are no significant differences between the decisionmaking abilities of adults and late adolescents. Thus, Susan Silverberg and Dawn Gondoli (1996: 50) write that 'the evidence available to date suggests that adolescents - at least once they reach age 16 - have acquired a host of critical decision-making skills that are comparable to those of adults'. ${ }^{2}$ Based on empirical evidence, too, Gareth Matthews (2009: 175) expresses doubts about allowing 'the quite understandable focus on development psychology to structure completely our conception of children or our relationship with them', and in particular our judgements regarding their capacity for abstract, philosophical reasoning. In conclusion, there is a lot that is wrong with positivism - but this does not mean that everything about it ought to be rejected.

\section{Science, research and 'power'}

Postmodernists, ethnoepistemologists, culturalists and critical constructivists have also sought to enlist support for their anti-positivist position from developments in 20th-century physics: 'The correspondence epistemology of positivism was kneed in the guts by Einstein's Special and General Theories of Relativity, quantum mechanics, Werner Heisenberg's uncertainty principle ... just to mention a few challenges of the last century' (Kincheloe, 2015a: xix). Kincheloe (2015a: xvi) continues:

The place the observer occupies in the web of reality, the values she holds, the epistemological, ontological, ideological and other perspectives she either consciously or unconsciously embraces all help to shape how 
a particular entity is viewed and interpreted. Indeed, after Einstein, quantum mechanics, Heisenberg ... the view that meaning resides simply in the phenomenon itself seems archaic.

Stanley Aronowitz (1988) similarly argues in his programmatically titled book Science as Power that science does not constitute a manifestation of universal reason but, on the contrary, 'situated' knowledge conditioned by the social, cultural and historical circumstances that have engendered it - an ideology that reflects the prevalent patterns of social power and dominance that extend well beyond the institutions of science. In particular, he appeals to the insights and challenges furnished by quantum mechanics and the uncertainty principle vis-à-vis the objectivity, universality and reliability of Western mainstream science. The argument is that, since the formulation of the uncertainty principle, it is no longer tenable that physics can provide reliable information about the physical world: it has forfeited its claim to objectivity and is now embedded in the changeable exegetics of knower-known (or subject-object) relations.

Gross and Levitt (1998: 51-52) point out that if Heisenberg and other quantum physicists had opted for a less suggestive name, this would have forestalled a considerable amount of misinterpretation and prevented misconceptions. They characterise the uncertainty principle as:

[a] predictive law about the behaviour of concrete phenomena than can be tested and confirmed like other physical principles. It is not some brooding metaphysical dictum about the Knower versus the Known, but rather a straightforward statement, mathematically quite simple, concerning the way in which the statistical outcomes of repeated observations of various phenomena may be interrelated ... when viewed as a law of physics, the uncertainty principle is a very certain item indeed. It is an objective truth about the world.

What are the epistemological and ethical implications of Albert Einstein's ground-breaking work on a new theory of time and space that later became known as the theory of relativity? Does it also yield relativism, about knowledge and truth in the former instance, and about morals and values in the latter? If the observer is a physically central part of the world she is describing, what bearing - if any - does this have on knowledge and truth, morals and values - concerning, for example, facts about the shape of the earth and values like human rights? It is sometimes assumed that it implies both relativism about knowledge and truth and relativism about values. Einstein had distinct ideas about the responsibilities of scientists and the implications of their work as well as of science in general, epistemological and ethical, ideas none of which amount to a validation of relativism. The implication that Einstein's theory of relativity was anti-universalistic (Kincheloe and Tobin, 2015b: 21) rests on a profound misunderstanding of Einstein's views. Speaking about the fundamental role of the university, in a tape recording made in Princeton in 1951, Einstein said (2003, CD 2, track 7):

The institution of universities is based on the ideal of universality in its widest sense, universality of the domain of enquiry, striving for truth, unaffected by extraneous aims, intentions or prejudices. Striving for universality of the spirit, unrestrained by national or other political motivations. In short, what matters is the striving for universality of mind and spirit. It is no secret that we have been far more successful in developing the mind than in developing the personality. It seems that even the quest for knowledge is threatened by lack of persons of a truly universal spirit. If the universities remain true to their fundamental task, they may contribute significantly to the solution of the crises which threaten us today.

Shifting the focus to the hegemonic abuse of (epistemological) power, Kincheloe and Tobin (2015a: 9) point out that 'Western culture and Western colonised cultures do not present a homogeneous way of life but a domain of difference shaped by unequal power relations' (see also Steinberg, 
2015: 128; Kincheloe, 2015b: 279, 281). Questions concerning the exact nature or identity of 'Western culture' notwithstanding, the hegemonic abuse of power is obviously morally problematic. Kincheloe (2015a: xix) emphasises the need to stand up against 'episto-oppression' and 'epistemological colonialism' that operate 'to invalidate the information constructed by peoples from oppressed locales and replace them with Eurocentric crypto-positivistic knowledges'. He is surely right about one thing: aided in no small way by positivism and behaviourism, 'Western' knowledge, science, technology and 'rationality' have led to, or have had as a significant goal, the subjugation of nature, and so far have been devastatingly efficient. First, the pursuit of nuclear energy, wholesale deforestation and destruction of fauna and flora, intensive farming of animals for human consumption, animal experimentation ${ }^{3}$ and the obsession with growth are deplorable and - indeed - irrational. Second, the marginalisation of indigenous peoples' practices, skills and insights has, to a large extent, been arrogant and of similarly questionable rationality. Third, current attempts by industrial and high-tech nations to (re)colonise or appropriate these practices, skills and insights for commercial gain are exploitative and contemptible.

As Harvey Siegel has indicated, the hegemonic abuse of power is customarily rejected on the basis of critical evaluation and compelling argument. It is not clear how any rejection of hegemonic imposition, any critique of dominant social power, can be coherent and consistent without advocates of alternative epistemologies employing these 'tools of mainstream philosophical thought' (Siegel 2012: 80). Or, as Elizabeth Rata puts it (2012: 102), by 'rejecting the idea of objectivity and by conflating what is known with who knows it', culturalism 'weakens the commitment to universal knowledge'. Because 'the "knower" and "knowledge" are not separated, there is no source for objectivity other than in the [researcher] him- or herself - a source easily rejected', which is one 'of the flaws in the relativist argument' (Rata, 2012: 103). Rata considers it ironical that, 'while culturalism rejects the concept of universalism, it is itself a universalist movement' (Rata, 2012: 104). Finally, relativism is clearly symmetrical. If it can be employed to protect the weak against the interpretational sovereignty of the powerful, then it can also be used to render the powerful immune to critique by the weak.

\section{'Culturally distinctive epistemologies' and 'critical constructivist epistemology'}

Kincheloe (2015a: xv) considers positivism's rejection of 'diverse epistemologies, ontologies, and research designs that allow us to bring the phenomenon into our range of perception' to be 'a form of parochial anti-intellectualism'. Particularly in recent years, the notions of epistemological diversity and culturally distinctive epistemologies have received increased attention. In his discussion of the ways and possibilities of preparing doctoral students for such diversity, Aaron Pallas (2001) states that one of the most confusing developments within educational research has been the proliferation of epistemologies, views about what constitutes knowledge in education, what serves as evidence for an assertion and what in turn warrants this evidence. Novices and experienced researchers alike seem to struggle trying to keep up with the 'plural manifestations of epistemology' (Odora Hoppers 2002: 18): naturalism, empiricism, positivism, postpositivism, epistemological foundationalism, antifoundationalism, relativism, standpoint theory and standpoint feminism within epistemology, and postmodernism, not to mention 'democratic epistemology' (Nkomo, 2000), 'multicultural epistemologies' (Banks, 1998), 'African'/'Afrocentric epistemology' (Asante, 1990, 2005; Bakari, 1997), 'feminist epistemology’ (Code, 2012; Harding, 1987, 1996), 'Chicana feminist epistemology’ (Delgado Bernal, 1998), 'Afrocentric feminist epistemology' (Hill Collins, 1990), 'sexist' or 'androcentric' and 'racist epistemologies' (Braidotti, 1991, 2006; and Scheurich 
and Young, 1997, respectively), as well as 'women's' or 'gendered ways of knowing' (Belenky et al., 1986; Harding, 1996) and 'African' or 'native ways of knowing' (Dei, 2004; and Barnhardt and Kawagley, 2005, respectively). Pallas (2001) considers these different epistemologies to be central to both production and consumption of educational theory and research. Given that they inform all phases of the research process, engagement with them is essential for learning the craft of research in the course of one's studies. These epistemologies, moreover, shape the ability of academics to understand and appreciate the research of others. Such an appreciation is a precondition for any scholarly discourse that guides the success of collective learning within a particular field (Pallas, 2001). If educational researchers did not understand or could not engage with one another, both within and beyond an educational research community, then the whole enterprise would be likely to fail resoundingly. In order to circumvent a recurring pattern of epistemic inflexibility, educational researchers therefore need to engage with a multitude of epistemological perspectives and approaches, until the representatives of different educational research methodologies understand one another - in spite or perhaps because of their differences. Pallas (2001) considers it to be one of the most important tasks of universities to prepare emerging educational researchers for such epistemological diversity.

Referring both to 'different knowledges that might challenge the status quo' (Kincheloe and Tobin, 2015b: 15) and to 'diverse ways of seeing and making meaning', Kincheloe and Tobin (2015a: 4) state that educational researchers guided by these:

[m]ultiple perspectives understand relations between values and different interpretations of the world in general and education in particular. They understand the way one's location in the world or position in the web of reality (e.g. one's race, class, gender, sexuality, religion, ideology, epistemology, etc.) helps shape how one sees self and world. Educational researchers who do not understand these dynamics of positionality (the way one is situated in the world) and their impact on the questions we ask of education, schooling, politics, etc. are babes in the research woods. Their claims to objectivity fall on fallow ground.

This exemplifies the increasingly popular view that ethnic or cultural groups have their own distinctive epistemologies, that epistemologies are also gendered and that these have been largely ignored by the dominant social group. A corollary of this view states, as we saw above, that educational research is pursued within a framework that represents particular assumptions about knowledge and knowledge production that reflect the interests and historical traditions of this dominant group. Kincheloe and Tobin (2015a: 7) contend that 'given different values, different ideologies, and different positions in the web of reality, different individuals will interpret what is happening differently. We never stand alone in the world, especially when we produce knowledge'. Kincheloe (2015a: xx) considers it impossible 'to separate knowing and being', which implies that 'particular phenomena can only be understood when the knower has become aware of her context and the way it shapes her particular lens'. Moreover, the 'epistemologies, ontologies, and multiple research methodologies we embrace understand that educational phenomena are situated in environments constructed by their temporal interactions with the other dynamics in the web of reality' (Kincheloe and Tobin, 2015b: 25).

Are all interpretations of educational events and phenomena equally valid and legitimate? Is there no way to adjudicate between different knowledge claims, between different values and ideologies? Apart from rendering knowledge and truth relative, ${ }^{4}$ Kincheloe and Tobin also seem to imply that there are no common or universal values, and that different values are incommensurable. This is a difficult position to maintain not only about ethical values but also about values in research. Originality, open-mindedness, fair-mindedness and sincerity are surely universal, even if they are not absolute. Kincheloe and Tobin's account is also noteworthy for the use of 'web of 
reality' in the singular. 'Web of reality' indicates the complexity of reality - but without logically implying that such complexity constitutes multiplicity. 'Reality' normally exists independently of the researcher's personal perceptions and beliefs, independently of socially or culturally constructed ideas. But, Kincheloe and Tobin continue:

Understanding, describing, and even critiquing the existing state of affairs does not mean that we must retreat to the positivist land of nowhere. We can understand, describe, and critique but always from a specific time and location. (Kincheloe and Tobin, 2015b: 28; see also Holzmeyer and Willinsky, 2015: 467)

Even if objectivity is ultimately impossible to achieve, given researchers' temporally and spatially circumscribed existence, necessary perspectivalism and positionality, this surely cannot mean that the procedures for understanding and describing reality, and indeed for critique, follow an 'anything goes' conception or that researchers should not at least strive for objectivity, in order for this understanding, description or critique to be compelling beyond this particular time and location. ${ }^{5}$

The not-so-subtle move is now from the positioned, situated, 'embedded' self of the conscious individual researcher to the necessary personal, social and cultural constructedness of the world, the cosmos - that is, of reality.

The idea that there exists in the atemporal ether a true meaning of a phenomenon is baffling, as we observe an ever changing and interacting educational world in process. The meaning of an educational event is always in the process of negotiation among divergent researchers, emic and etic observers, and various other parties. (Kincheloe and Tobin, 2015b: 27)

Again, would this mean that we cannot judge, evaluate or compare 'educational events'? Kincheloe and Tobin (2015b: 22; emphasis added) both believe that 'there should be diversity in the ways that knowledge is produced and greater toleration and respect for multiple methodologies and designs'. Apart from making diversity of knowledge production a normative rather than a factual matter, this suggests, at the very least, that the requisite toleration and respect are universal values. At the same time, the authors 'assert that researchers producing any form of knowledge should understand and make it clear to their audiences the nature of the knowledge they are producing'. Given the fact that 'our selfhood is deeply embedded in the research process', Kincheloe and Tobin (2015b: 27-28) write that:

[w]e begin to realise that the quality, the viability of the information we produce does not depend on an objective correspondence to the 'objective reality' out there. Instead, it has to do with numerous understandings of the ways knowledge production operates, the nature of the constructed self, the role of socio-political and epistemological and ontological frameworks in which we all operate, and the relationship between these dynamics and the spatio-temporal processes that we are researching.

This is surely a non sequitur - and rather questionable to boot: do the information and knowledge we produce really have nothing at all to do with what there really is (out there)?

Regarding the assumption that the self is necessarily embedded in the research project, the task would be "to rigorously study the construction of selfhood, the socio-cultural and political relations of the knower, in the process bringing our understanding of the knower back to her inseparable relationship with the known' (Kincheloe, 2015a: xxxii). Kincheloe claims that cultural location matters profoundly in this context: 'The difference of worldviews and ways of seeing and being of [different] individuals can help us understand how divergent conceptual frameworks can change what we see about the world' (Kincheloe, 2015a: xxxii). He also refers to 'the insights we have 
developed about the social construction of knowledge and knowledge production' (Kincheloe, 2015a: xiv). With Tobin he argues that in repudiating 'hyperrationalistic notions that there is a monolithic knowable world explained by positivist science, an epistemology of complexity views the cosmos as a human construction, a social creation' (Kincheloe and Tobin, 2015a: 8). The authors then furnish the following account of critical constructivism:

An epistemology of constructivism has maintained that nothing represents a neutral perspective, in the process shaking the epistemological foundations of modernist Cartesian grand narratives. Indeed, no truly objective way of seeing exists. Nothing exists before consciousness shapes it [into] something we can perceive. What appears as objective reality is merely what our mind constructs, what we are accustomed to seeing. The knowledge that the world yields has to be interpreted by men and women who are part of that world. (Kincheloe and Tobin, 2015a: 8)

It should be clear that the view that the world, the cosmos, that is objective reality, is a human construct cannot, for reasons of consistency, be presented as a grand narrative, as transcontextual, transcultural knowledge. But, if this view is itself a non-neutral human construct, it is not necessarily compelling to others, given their respective temporal and spatial positionality.

According to Steinberg (2015: 122), 'Critical poststructuralist theory is committed to a theoretical stance that guarantees the individual or community the capacity to make meaning and to act independently'. She concludes that 'any theory acceptable to critical poststructuralists [...] must take into account local divergence'. However, if the usefulness of theory 'is always mitigated by context', and if 'theory does not travel well from context to another', then the same must also apply to critical poststructuralist theory. It is then unclear why it should be considered compelling by those outside the context that mitigates the usefulness of critical poststructuralism.

\section{Research as 'bricolage'}

A distinctive feature of both critical constructivism and critical poststructuralism appears to be its account of research as bricolage. The latter idea - tinkering, trying out, using available tools to assemble or construct from a diverse range of available materials - and its proximity to epistemological and methodological diversity has been embraced by several authors (Berry, 2015; Kincheloe, 2015a; Smith, 1999; Steinberg, 2015). Bricoleurs act in 'the spirit of multilogicality', here understood as the opposite of monologicality, as involving different 'logics of inquiry', that is as involving a multitude of epistemologies, rather than one dominant epistemological paradigm and form of inquiry (Berry, 2015; Kincheloe, 2015a: ix, xvii, 2015b; Kincheloe and Tobin, 2015b: 22; Tobin and Steinberg, 2015a: xl). In contrast to 'what crypto-positivist researchers label reality', which 'is actually more like a belief about what the world is - as conviction grounded on passing glimpses', what bricoleurs 'call reality exists in the intersection of the universe with the mind - a key dimension of what the bricolage studies' (Kincheloe, 2015a: xv). For bricoleurs there appears to exist no mind-independent reality: 'The critical complex epistemology promoted by Steinberg's and Berry's bricolage questions the declaration that there exists one fixed external world of real things' (Kincheloe, 2015a: xviii). Inspired by 'the spirit of quantum theory' and related developments in physics:

[b]ricoleurs posit that the phenomena of the world never have fixed, set meanings ... in the everyday lived world of the researcher ... physical and social phenomena don't have an eternal Platonic form, a permanent spatial arrangement that persists as time passes. This where the complexity theoretical notion of process enters the bricolage's understanding of objectivity vis-à-vis epistemology and ontology. As a part of larger 
contexts and processes, the phenomena of the world are always changing, ever in process in act of becoming. (Kincheloe, 2015a: xvi)

Yet, if all 'knowledge is contingent and always open to change when someone asks new questions from a different perspective' (Kincheloe, 2015a: xviii), then what about this particular claim to knowledge? If 'all epistemologies, all logics of inquiry are grounded upon a particular view of the world whether the researcher is conscious of it or not' (Kincheloe and Tobin, 2015b: 22), then why should this be compelling to someone who does not share this particular view of the world?

The notion of culturally distinctive epistemologies is sometimes, misleadingly, used in the sense of distinctive research method(ologie)s. Research questions and methods vary, of course, but Siegel (2012: 68-74) points out that this should not be taken to imply some kind of methodological relativism. For example, Margaret Kovach (2010: 39) contends that indigenous methodologies 'are guided by tribal epistemologies, and tribal knowledge is not Western knowledge. Knowledge is neither acultural nor apolitical' (see also Smith, 1999). And according to Kathleen Berry (2015: 87), 'Entry into the multiple theories, discourses and practices that a bricoleur can use to construct the research is different each time and for each person'. Bricolage 'is as much about conflict of ideologies, theories, methodologies, discourses and practices as it is about multiplicity of those areas' (Berry, 2015: 93). It challenges theories and methodologies that peddle grand narratives - that is, 'claims to absolute truth, meaning, and knowledge' (Berry, 2015: 94). Siegel's argument against the kinds of view expressed here is that compelling judgements can be made about the quality of competing research methodologies. Some are better than others, and some are plainly invalid. A revealing statement in this regard stems from Berry (2015: 88), who considers the 'most difficult aspect of doing research as bricolage' to be 'the writing: that is, how to shape and format a text that avoids the linear, reductionist structure of traditional research thesis or report'. Does this mean that one should also avoid conventions like 'proper' referencing and citation, reasoned argument, justified or supported assertions, and the like? 'Bricolage' is often used to connote creative craftwork or handiwork. When related to research, it could also be viewed, less favourably, as botchery or charlatanry.

With regard to what bricoleurs in education can learn from critiques of 'Western ways of seeing and their socio-political and pedagogical effects', Kincheloe (2015a: xix-xx) considers it:

[e]ssential to human welfare, educational legitimacy, and the well being of the planet itself that educational researchers understand the effects of this epistemology of correspondence and the variety of ways it is deployed to exacerbate human oppression and pathological educational practices.

Contra Kincheloe, however (over and above the difficulty of establishing a causal connection with oppression), 'correspondence' is no longer the default position within the 'Western' epistemological canon. David Bridges (1999) has argued, quite compellingly, that different theories of truth might be seen to fit different areas of knowledge or (educational) research models - without implying relativism about truth. For example, the correspondence theory of truth seems to have its natural home in at least some of the empirical sciences, while the coherence theory of truth pertains, for example, to mathematics and symbolic logic. The pragmatist theory of truth (with utility as its characteristic mark, that is, a proposition is true if it is useful to believe) is appropriate for technology and certain applied sciences, whereas the consensus conception of truth has a distinct appeal in the realm of social and political decision-making and is also relevant in matters of aesthetics and taste. It follows that the assumption of correspondence truth and correspondence epistemology being the default conception within 'Western' scientific and, in our case, educational research, is rather narrow and indeed mistaken.

Carolyne Ali-Khan (2015: 294) acknowledges that her 'students initially (and sometimes persistently) find it difficult to critique a relativist stance that supports every position'. Yet, she also 
endorses what has been called 'autoethnographic research' as a 'liberating rather than domesticating pedagogy', because of its potential, inter alia, to 'push back on repressive regimes of truth' and to 'challenge the idea that there are simple truths that can be distilled from lived experiences' (Ali-Khan, 2015: 296). It is difficult to reconcile her earlier complaint with this conception of truth as idiosyncratic, pliable and slippery - as messily complex and indeed multitudinous, and with her rejection of 'conceptions of a single objective reality that can be measured and represented uniformly' (Ali-Khan, 2015: 295). She approvingly quotes the view held by Owen et al. (2009) that truth is always an inherent unstable variable, that factual truths ought to be contrasted with ideas that are true, and that "truth" in the scientific sense may not be of paramount importance in the quest to understand personal (autoethnographic) experience or the larger world' (AliKhan, 2015: 308). If 'ideas that are true' refer to beliefs, then the requirement to distinguish them from factual truths is certainly plausible. It then turns out, however, that it is not truth that is 'an inherently unstable variable', but rather belief, which is the subjective component of propositional knowledge.

\section{Commitment to truth, impartiality and respect for evidence}

Commitment to pursuing the implications of rational argument and the exigencies of impersonal rational principles (commitment to truth, impartiality, respect for evidence and the like) arguably remain key in educational research. Criticisms of evidence-based research, objective knowledge, rational inquiry and impersonal rational principles face substantial difficulties, since they appear to presuppose what they want to reject. In an argument that could also be advanced against defenders of culturally distinctive epistemologies, critical constructivism, multilogicality and the like, Siegel (1998: 30) contends that postmodernism, for example:

[w]ants to reject the possibility of objective knowledge but apparently regards it as an objective fact about the world that a subject's knowledge of the world is always pre-interpreted and that knowledge is therefore never objective ... Similarly, the postmodernist insistence that there is 'no privileged position that enables philosophers to transcend the particularities of their own cultures and traditions' seems itself an attempt to speak from such a position, since it seems to be making an assertion concerning all philosophers, cultures, and traditions.

Whether the postmodernist response is one of denial, refutation or 'radical doubt', its expression requires adherence to 'the standards and rhetoric of argumentation' (Burbules, 2009: 528). Nicholas Burbules (2000) advises that we should not minimise real points of difference or disagreements between these contrasting views, but he also reminds us that it seems inconsistent with the philosophical spirit of inquiry to rule out of hand the possible insights or benefits of any serious philosophical view or that specific points of insight cannot be generatively reinterpreted or translated from one tradition to another. However, the 'greater tolerance and respect for multiple methodologies and designs' and for 'culturally distinctive epistemologies' that are demanded by Kincheloe and Tobin (2015b: 22) do not translate into unquestioning acceptance of untruths and inconsistencies. The philosophical spirit of scholarly disputation requires remaining faithful to the possibility of critical interrogation, discussion and argument about even the most difficult educational issues, as well as to some standard of good reasoning about ontological, epistemological and ethical matters in education, as in other areas of public concern and intellectual life.

\section{Declaration of conflicting interests}

The author declared no potential conflicts of interest with respect to the research, authorship, and/or publication of this article. 


\section{Funding}

The author received no financial support for the research, authorship, and/or publication of this article.

\section{Notes}

1. In this regard, it is also worth considering Dylan Evans's (2001) intriguing idea of a universal emotional subject, that is, that our common emotional heritage binds humanity together in a way that transcends cultural differences.

2. For similar research and citation of relevant neurological evidence, see Reich (2009: 484, n.13). There is clearly a difference between claiming that this is all there is to educational research and seeing empirical research and evidence-based inquiry as a significant field within educational scholarship.

3. Contrary to what Gross and Levitt maintain (1998: 196-203), animal experimentation for medical, pharmacological, military and commercial purposes - apart from its highly questionable morality - is evidently bad science (Horsthemke, 2010: 91-104).

4. I have dealt extensively with the problems of relativism and superstition in accounts of indigenous knowledge elsewhere (Horsthemke, 2004a, 2004b, 2014).

5. See also Cox (1981: 128) and Knafo (2016).

\section{References}

Ali-Khan C (2015) Liberation, mice elves and navel gazing: Examining the ins and outs of autoethnography. In: Tobin K and Steinberg S (eds) Doing Educational Research, 2nd edition. Rotterdam, Boston, Taipei: Sense Publishers, pp.293-319.

Aronowitz S (1988) Science as Power: Discourse and Ideology in Modern Society. Minneapolis: University of Minnesota Press.

Asante MK (1990) Kemet, Afrocentricity and Knowledge. Trenton: Africa World Press.

Asante MK (2005) African ways of knowing and cognitive faculties. In: Asante MF and Mazama A (eds) Encyclopedia of Black Studies. Thousand Oaks: SAGE.

Bakari RS (1997) Epistemology from an Afrocentric perspective: Enhancing black students' consciousness through an Afrocentric perspective. Lincoln, USA: University of Nebraska - Lincoln. Available at: http://digitalcommons.unl.edu/pocpwi2/20 (accessed 20 March 2019).

Banks JA (1998) The lives and values of researchers: Implications for educating citizens in a multicultural society. Education Researcher 22(5): 4-14.

Barnes J (1997) Cross Channel. Basingstoke: Picador.

Barnhardt R and Kawagley AO (2005) Indigenous knowledge systems and Alaska native ways of knowing. Anthropology and Education Quarterly 36(1): 8-23.

Belenky MF, Clinchy BM, Goldberger NR, et al. (1986) Women's Ways of Knowing: The Development of Self, Voice, and Mind. New York: Basic Books.

Berry K (2015) Research as bricolage: Embracing relationality, multiplicity and complexity. In: Tobin S and Steinberg S (eds) Doing Educational Research, second edition. Rotterdam, Boston, Taipei: Sense Publishers, pp.79-110.

Braidotti R (1991) Patterns of Dissonance: A Study of Women in Contemporary Philosophy. New York: Routledge.

Braidotti R (2006) Transpositions: On Nomadic Ethics. Cambridge, UK: Polity Press.

Bridges D (1999) Educational research: Pursuit of truth or flight of fancy? British Educational Research Journal 25(5): 597-616.

Burbules N (2000) Postmodernism for analytic philosophers of education. Educational Philosophy and Theory 32(3): 311-314.

Burbules N (2009) Postmodernism and education. In: Siegel H (ed.) The Oxford Handbook of Philosophy of Education. Oxford: Oxford University Press, pp.524-533.

Code L (2012) Taking subjectivity into account. In: Ruitenberg CW and Phillips DC (eds) Education, Culture and Epistemological Diversity: Mapping a Contested Terrain. Dordrecht: Springer, pp.85-100. 
Cox RW (1981) Social forces, states and world orders: Beyond international relations theory. Millennium: Journal of International Studies 10(2): 126-155.

Dei GJS (2004) Learning culture, spirituality and local knowledge: Implications for African schooling. International Review of Education 48(5): 335-360.

Delgado Bernal D (1998) Using a Chicana feminist epistemology in educational research. Harvard Educational Review 68(4): 555-582.

Einstein A (2003) The fundamental task of the university. Verehrte An-und Abwesende! Originaltonaufnahmen 1921-1951. Cologne: Supposé Audio CDs.

Evans D (2001) Emotion: A Very Short Introduction. Oxford: Oxford University Press.

Gross PR and Levitt N (1998) Higher Superstition: The Academic Left and its Quarrels with Science, second edition. Baltimore: Johns Hopkins University Press.

Harding S (1987) Conclusion: Epistemological questions. In: Harding S (ed.) Feminism and Methodology. Bloomington: Indiana University Press, pp.181-190.

Harding S (1996) Gendered ways of knowing and the 'epistemological crisis' of the West. In: Goldberger NR, Tarule JM, Clinchy BM and Belenky MF (eds) Knowledge, Difference, and Power: Essays Inspired by Women's Ways of Knowing. New York: Basic Books, pp.431-454.

Hill Collins P (1990) Black Feminist Thought: Knowledge, Consciousness, and the Politics of Empowerment. New York: Routledge.

Holzmeyer C and Willinsky J (2015) From scientific research in education to the 'open science' movement. In: Tobin K and Steinberg S (eds) Doing Educational Research, second edition. Rotterdam, Boston, Taipei: Sense Publishers, pp.455-472.

Horsthemke K (2004a) Indigenous knowledge: Conceptions and misconceptions. Journal of Education 32: $31-48$.

Horsthemke K (2004b) Knowledge, education and the limits of Africanisation. Journal of Philosophy of Education 38(4): 571-587.

Horsthemke K (2010) The Moral Status and Rights of Animals. Johannesburg: Porcupine Press.

Horsthemke K (2014) Some doubts about 'indigenous knowledge', and the argument from epistemic injustice. Quest 25(1-2): 49-76.

Kincheloe JL (2015a) Foreword: Pearls of wisdom. In: Tobin K and Steinberg S (eds) Doing Educational Research, second edition. Rotterdam, Boston, Taipei: Sense Publishers, pp.ix-xxxviii.

Kincheloe JL (2015b) Critical historiography. In: Tobin K and Steinberg S (eds) Doing Educational Research, 2nd edition. Rotterdam, Boston, Taipei: Sense Publishers, pp.279-291.

Kincheloe JL and Tobin K (2015a) Doing educational research in a complex world. In: Tobin K and Steinberg S (eds) Doing Educational Research, second edition. Rotterdam, Boston, Taipei: Sense Publishers, pp.3-13.

Kincheloe JL and Tobin K (2015b) The much exaggerated death of positivism. In: Tobin K and Steinberg S (eds) Doing Educational Research, second edition. Rotterdam, Boston, Taipei: Sense Publishers, pp.15-32.

Knafo S (2016) Bourdieu and the dead end of reflexivity: On the impossible task of locating the subject. Review of International Studies 42: 25-47.

Kovach M (2010) Indigenous Methodologies: Characteristics, Conversations, and Contexts. Toronto: University of Toronto Press.

Matthews R (2009) Philosophy and developmental psychology: Outgrowing the deficit conception of childhood. In Siegel H (ed.) The Oxford Handbook of Philosophy of Education. Oxford: Oxford University Press, pp.162-176.

Nkomo M (2000) Educational research in the African development context: Rediscovery, reconstruction and prospects. In: Higgs P, Vakalisa NCG, Mda TV and Assié-Lumumba NT (eds) African Voices in Education. Lansdowne: Juta, pp.47-62.

Odora Hoppers CA (2002) Indigenous knowledge and the integration of knowledge systems: Towards a conceptual and methodological framework. In: Odora Hoppers CA (ed.) Indigenous Knowledge and the Integration of Knowledge Systems: Towards a Philosophy of Articulation. Claremont: New Africa Books, pp.2-22. 
Owen JAT, McRae C, Adams T, et al (2009) Truth troubles. Qualitative Inquiry 15(1): 178-200.

Pallas AM (2001) Preparing education doctoral students for epistemological diversity. Educational Researcher 30(5): 6-11.

Pring R (2000) Philosophy of Educational Research. New York and London: Continuum.

Rata E (2012) The Politics of Knowledge in Education. New York and London: Routledge.

Reich R (2009) Educational authority and the interests of children. In: Siegel H (ed.) The Oxford Handbook of Philosophy of Education. Oxford: Oxford University Press, pp.469-485.

Scheurich J and Young M (1997) Colouring epistemologies: Are our research epistemologies racially biased? Educational Researcher 26(4): 4-16.

Siegel H (1998) Knowledge, truth and education. In: Carr D (ed.) Education, Knowledge and Truth: Beyond the Postmodern Impasse. London: Routledge, pp.19-36.

Siegel H (2012) Epistemological diversity and education research: Much ado about nothing much? In: Ruitenberg CW and Phillips DC (eds) Education, Culture and Epistemological Diversity: Mapping a Contested Terrain. Dordrecht: Springer, pp.65-84.

Silverberg S and Gondoli D (1996) Autonomy in adolescence: A contextualised perspective. In Adams G, Montemayor R and Gullotta T (eds) Psychosocial Development During Adolescence. Thousand Oaks: SAGE.

Smith LT (1999) Decolonizing Methodologies: Research and Indigenous Peoples. New York: Zed Books.

Steinberg S (2015) Proposing a multiplicity of meanings: Research bricolage and cultural pedagogy. In: Tobin K and Steinberg S (eds) Doing Educational Research, 2nd edition. Rotterdam, Boston, Taipei: Sense Publishers, pp.111-132.

Tobin K and Steinberg S (2015a) Foreword to the second edition. In: Tobin K and Steinberg S (eds) Doing Educational Research, 2nd edition. Rotterdam, Boston, Taipei: Sense Publishers, pp.xxxix-xliii.

Tobin K and Steinberg S (eds) (2015b) Doing Educational Research, 2nd edition. Rotterdam, Boston, Taipei: Sense Publishers.

\section{Author biography}

Kai Horsthemke is an associate professor and teaches philosophy of education at KU Eichstätt-Ingolstadt in Germany. He is also a visiting professor in the School of Education at the University of the Witwatersrand, South Africa, and a fellow at the Oxford Centre for Animal Ethics, UK. He is the author of three monographs, The Moral Status and Rights of Animals (Porcupine Press, 2010), Animals and African Ethics (Palgrave Macmillan, 2015) and Animal Rights Education (Palgrave Macmillan, 2018), and, together with Peggy Siyakwazi, Elizabeth Walton and Charl Wolhuter, the co-editor of the first two editions of Education Studies (Oxford University Press Southern Africa, 2013 and 2016, respectively). 